\title{
Adiciones Bibliográficas
}

\author{
Por Roberto M. Tisnés J., C.M.F.
}

En el $N^{9} 111$ de esta Revista (Vol. XXXII, $1^{9}$ y $2^{9}$ trimestre de 1971, págs. 257-275), apareció mi estudio El Seudónimo en Colombia, a propósito y como glosa adicional a la obra del Dr. Rubén Pérez Ortiz, Seudónimos Colombianos (Instituto Cairo y Cueivo, Bogotá, 1961).

En realidad, ambos trabajos se refieren a la bibliografía del seudónimo en Colombia. La investigación de Pérez Ortiz aparece publicada como volumen II de la serie bibliográfica del benemérito Instituto que lleva los nombres de dos de las más altas cifras humanistas de Colombia: Miguel Antonio Caro y Rufino José Cuervo.

Omití recordar, al comentar la obra de Pérez Ortiz, que debió ser más amplia y documentada en lo referente a la historia -a ser posible de cada seudónimo- o al menos en cuanto a la indicación - siquiera incompleta - de las obras y publicaciones donde fue utilizado.

Claro que esta tarea impone mayor tiempo de elaboración para una obra. Pero se justificaba, porque venía a ser y se lograba con ella, una verdadera historia del seudónimo en Colombia.

La obra de Pérez a pesar de su importancia, no deja de ser una especie de catálogo de seudónimos, un esqueleto que debería ser llenado al menos un poco con la carne de datos alusivos histórico-literarios.

Así lo han verificado pocos pero escogidos investigadores.

Tal el caso, antiguo ya, del francés A. A. Barbier (1765-1825), quien en los años 1806-1808 publica la primera edición de 4 volúmenes de su Diccionaire des anonymes et des seudonymes, con un total de más de 12.000 notas bibliográficas.

La segunda edición ve la luz en los años 1822-1827 con más de 23.000 referencias. La tercera, debida a su hijo Olivier y a René y Paul Billard, aparece en los años 1872-1879.

El gran polígrafo chileno Don José Toribio Medina, tiene una obra sobre el seudónimo americano, clásica como todas las suyas. Y un escritor uruguayo, cuyo nombre no recordamos, otra similar sobre su patria.

Vale la pena añadir que obras como éstas y otras sobre temas similares, nunca pueden ser perfectas ni definitivas, y constituyen en 
realidad el dolor de cabeza y preocupación de sus autores. Pero sí admiten una relativa exhaustez en su investigación y perfeccionamiento.

Claro que una vez publicadas, pasarán varios años antes de que un nuevo "chiflado" por el tema, vuelva sobre él para adicionarlo y perfeccionarlo. Y no serán pocos los casos en que, por desgracia, la publicación producto de muchas labores y vigijias, quede tal como apareció en su primera edición, porque nadie tuvo la buena voluntad, el interés y el valor de volver sobre un tema anteriormente explorado, aunque ciertamente susceptible de glosas y adiciones, mejoras y perfeccionamientos.

Pero no pretendo en esta oportunidad detenerme una vez más en la obra de Pérez Ortiz. Sí, solamente, recordar y adicionar los volúmenes V y VIII de la serie bibliográfica del Instituto Caro y Cuervo, dedicados a Rafael Pombo y a Jorge Isaacs.

$Y$ primeramente el volumen dedicado a Rafael Pombo.

Héctor Orjuela, colaborador del Instituto, elaboró el volumen dedicado por el Departamento de Bibliografía a la figura y obra de Rafael Pombo (1833-1912). Biografía y Bibliografía de Rafael Pombo, con la colaboración en la parte bibliográfica de Rubén Pérez Ortiz, es el título del volumen que pretendo reseñar y acrecer levemente (420 pás., Bogotá, 1965).

No sobra recordar que la bibliografía es total, quiero decir, bibliografía pombiana (págs. 99-331) y sobre Pombo (págs. 333-400). Va precedida por la biografía del gran poeta (págs. 1-97).

El número de páginas a la bibliografía dedicadas, señala la prolija investigación realizada.

En la Introducción, el autor nos hace saber que su obra "es el resultado de las investigaciones que por varios años he hecho sobre Rafael Pombo, y que me llevaron a dedicarle una extensa tesis doctoral terminada en $1960 .$. Hay que advertir, en cuanto a la biografía, que por complementarse ésta con el estudio general, es de suyo concentrada y presenta algunas lagunas que en la tesis, próxima a publicarse, reciben adecuada atención en secciones destinadas a estudiar las diversas modalidades de la producción en verso y prosa del poeta" (pág. VII).

Ciertamente el quehacer histórico de Pombo, da, según creo, para una mayor investigación biográfica por la importancia del personaje, la época en que vivió y hasta por los no escasos años de existencia.

En las páginas siguientes (VIII-XI), el autor se refiere a la historia de la obra y al proceso seguido en la elaboración de la bibliografía. A pesar del gran esfuerzo investigativo, Orjuela no puede menos de reconocer que "este volumen... apenas alcanza a ser una introducción a la bio-bibliografía de Pombo, dados su importancia en las letras nacionales y el enorme volumen de su producción...". (págs. X-XI).

En realidad el aporte que pretendo hacer a este volumen es pequeño. Sin embargc lo creo importante.

Se trata de una carta de Rafael Pombo dirigida a su amigo el Sr. Lisandro Villalobos, residente en la población de Gutiérrez en el 
oriente cundinamarqués, y hallada en el Archivo Parroquial. Nadie pensará que en aquel lejano y casi desconocido poblado, hubiera podido existir un corresponsal del gran poeta. Pero así fue. Y sin más preámbulos, voy a transcribir la que estimo interesante misiva de uno de nuestros más grandes y memoriosos poetas. Dice así:

\section{Bogotá, agosto 10 de 1904 \\ Señor Don Lisandro Villalobos \\ Gutiérrez, o Chuntiva.}

Apreciado amigo:

Celebrando esta ocasión de escribir a Ud. para tener en retorno noticias de Ud. y de mi Sra. Concepción, pues Beatriz mi hermana y yo nada hemos sabido de Uds. en los cinco o seis años que hará que vimos aquí a su Señora por última vez, tenemos también que participarles que a fines de junio Beatriz recibió una carta del Sr. D. Teófilo Gómez, Párrooo de Fosca (a quien no conocemos) preguntándole por el número de piezas de una vajilla de loza fina que "personas de crédito" dice él le han asegurado que Beatriz y otra Señora dieron a Ud. para la iglesia de Gutiérrez o para el servicio de la casa del Cura "y que Ud. dispuso de ellas vendiéndolas muy baratas como cosa propia", y pide que le avise de otras cosas que le dieran para ese piadoso objeto.

La respuesta de Beatriz se demoró un mes por duelos que hemos tenido en la familia, como la enfermedad y muerte de Juanita nuestra hermana menor, de Teodorito Valenzuela, excelente sobrino hijo de Felisa nuestra hermana, casado con Julia Grau hija de Don Eladio, y últimamente de nuestra tía Pepita Pombo, en Popayán, la hermana menor de nuestro padre. Además de los cuidados y visitas que estas desgracias nos trajeron, Beatriz sufre de varios achaques y yo pasé veinte y tres días en cama con un tercer ataque de bronquitis, en junio y julio, y ahora me repitió, y para satisfacer al Doctor Gómez y el buen crédito de Ud. era necesario preguntar a todos los vecinos nuéstros y conocidos de Ud. de que tuviésemos noticia.

En las salidas que pudimos hacer Beatriz y yo fuimos de casa en casa cumpliendo este grato deber, y en carta (de fecha 12 de julio pero concluída muchos días después por la necesidad de hacerla lo más completa posible), contestamos la del Sr. Dr. Gómez, que él recibió aquí mismo hace pocos días en la casa arzobispal, a donde él indicó que la dejáramos.

Beatriz contestó, por supuesto, la pura verdad, declarando que ni ella, ni persona alguna que haya visto, le dieron jamás a Ud. ni a mi Se ̃̃ora pieza alguna de loza. Que ella no les dió sino un pico de albañil, unos vidrios desiguales y un mantel y sobremantel que podían servir para la iglesia cuando estuviera concluída, o disponer Ud. de ellos io de su valor a discreción suya; y añadió que Uds. generosamente nos habían hecho el obsequio de un buen reloj inglés de campana que nos había servido mucho.

A $a$ u testimonio añadió el del Sr. Dr. Vargas, párroco de las Nieves, y de la Señora Solcdad su hermana, que tenían grande aprecio por Ud. y satisfacción en hospedarlo a veces en su casa cuando venía; el de la Señorita María Luisa Dueñas, que apenas le dió una o dos vi- 
telas sagradas, en papel; el de la Señorita Alejandrina Lago que sólo le diú una (sic) vidrios para ventana, y añadió que Ud. estaba autorizado por los Ilmos. Arzobispos Arbeláez y Herrera (lo cual repitió el último leyendo la carta de Beatriz que se le presentó abierta); el de la Señora Rosa Díaz, que dice que solo dió a Ud. unas novenas viejas; el de las señoras vecinas Estradas, Santos, Monnoys y Tobar de Carrillo, de que nada habían dado a Ud., ni Ud. les había pedido; el muy importante de Don Matías Delgado, tan benéfico y activo, y dijo que era increíble que hubiera quién chistara contra Ud., admirable socio de San Vicente de Paúl, jefe de una de sus escuelas gratuitas, y que debía a Ud. la enseñianza de un hijo, como él se lo había pedido, y sin embargo no había obsequiado a Ud. sino una docena de catecismos de la doctrina; y en fin, del R. P. Fray Jacinto Avila, franciscano eminente, quien dijo que no conocía hombre mejor que Lisandro Villalobos. Algunos dijeron que habían dado piezas de ropa vieja como para niños de las escuelas que Uds. formaban; y Beatriz añadió que una mujer que era quien solía llevarlas para el pueblo, había robado muchas. Y no clvidamos apuntar lo que debía a Ud. en su educación y carrera eclesiástica el Dr. Filiberto Avila. No mencionamos al albañil o arquitecto que Ud. llevó porque no lo conocemos y alguien dijo que él lo hostilizaba. También nos han hablado de un Sierra, de Cota, prestidigitador, que dió en muy devoto y dizque inició o hizo la obra de esa capilla y también fue calumniado ante el Sr. Arzobispo; y de una María Ramos que dizque conseguía estribos de cobre para hacer las campanas.

Deseamos que Ud. nos conteste dándonos noticias de Uds. y de todos sus progresos y persecuciones, que la Señorita Lago y nosotros ya sabemos que vienen de muy atrás, de la emulación y la envidia. Pero Dios premiará sus muchas buenas obras.

Deseándoles desde esta vida toda felicidad, tengan ésta como de Beatriz y de su Afmo. apreciador y amigo, Rafael Pombo (rúbrica).

(Archivo Parroquial de Gutiérrez. Libro Histórico de la Fundación de Gutiérrez, por Lisandro Villalobos. Comprende desde 1883 a 1904, pág. 125-126).

Simpática y sencilla, cordial y humana resulta esta carta del poeta bogotano. No trata ella de altas cuestiones poéticas o críticas, ni de trascendentales sucesos políticos. Simplemente comunica a un buen amigo lo que sobre él se dice, para iniciar, en su favor, una campaña de informes acerca de su personalidad y buenas actuaciones, y para desimpresionar a quienes se atrevieron, sin fundamento seguramente, a dudar de su honorabilidad. Sin duda hubo respuesta del Sr. Villalobos. Pero no la conozco.

Tan interesante a mi entender, resulta en la vida de un personaje como Pombo esta carta como cualquiera otra de más altos y repujados quilates literarios, críticos o sociales, o dirigida a más conspicuos personajes. Porque para la que denominaría biografía plena y total del hombre, rasgos humanos como el presente valen tanto y mucho más que otros datos $\mathrm{y}$ noticias. 


\section{Adiciones Bibliográficas}

Casualmente conocí la comunicación transcrita. Para que no se pierda y pueda quizá servir a la biografía del autor de las Fábulas, me he permitido reproducirla a modo de glosa y adición a la Biografía y Bibliografía de Rafael Pombo.

El volumen VIII de la serie bibliográfica del Instituto Caro y Cuervo, está dedicado a Jorge Isaacs. Lleva por título: Bibliografía sobre Jorge Isaacs (Bogotá, 1971, 102 págs.) y es un ensayo investigativo del estadinense Donald McGrady.

$\mathrm{Ni}$ qué decir tiene que es el primer intento de bibliografía isaacsiana, muy afortunado ciertamente, pues recoge 490 fichas, y rectifica y verifica no pocos datos anteriores. En buena hora llega esta publicación para los amantes de la ciencia bibliográfica, en momentos en que se ha llevado a cabo a la pantalla la novela María, que a pesar de sus años y del romanticismo que exhala, ha logrado superar la avalancha de la moderna novelística y merecer en pleno año de 1972 ser llevada al ccluloide, ante la convicción de los productores de que agradará y será probablemente un buen negocio.

Al repasar la publicación de McGrady, creí notar en ella la omisión de un folleto, muy escaso ciertamente, publicado en Medellín en 1905, en la Imprenta Oficial, con ocasión del traslado de los restos de Isaacs a la capital antioqueña. Mas sí fue citado por McGrady bajo el título de Varios (pág 53).

Consta el citado folleto de más de 30 títulos bibliográficos que el citado investigador se abstuvo de detallar, lo cual no me explico ciertamente. Ante la importancia de estas fichas bibliográficas, creo conveniente y útil reseñarlas en la presente oportunidad.

Conocida es la decisión del gran bardo y novelista de dejar sus restos a la tierra antioqueña, muy probablemente por su ascendencia judía y por el tradicional, aunque no probado en juicio, semitismo antioqueño.

En carta del 2 de agosto de 1893 al General Juan Clímaco Arbeláez, escribía Isaacs: "Mi querido Juan Clímaco: Te doy un estrecho abrazo. El expresa mucho de lo que anhelo decirte, como tu amigo de siempre y colombiano leal a la república.

"Honrándome demasiado, más de lo que puedo merecer, han publicado allá algunos amigos esa poesía a La Tierra de Córdoba, la tuya, la de tantos hombres ilustres, que bien merece mi amor y mi admiración. Ojalá no juzgues pobre y ruín la ofrenda mía: ha sido hecha con el alma.

"Te envío por este correo algunos ejemplares del canto. Házme el favor de poner en manos del General Vélez ese que va dedicado a él. Dios lo inspire y le ayude en su lahor redentora.

"Quizás te habrán dicho que deseo pasar en el valle de Medellín los últimos días de mi vida. Es ciertio. Bien pocos han de ser, porque los he gastado sin lástima en durísimas tareas.

"Si el éxito definitivo de mis trabajos sobre hulleras es satisfactorio, como es de esperarse, cumpliré aquel propósito. Pero el re- 
sultado es dudoso todavía y la expectativa cruel. En años y años sacrifiqué mi salud y arriesgué mi existencia, ansioso de procurarle al país cuantiosas riquezas y a mis hijos un modesto patrimonio. El pensar que, al morir yo, queden muy pobres y víctimas, por lo mismo, de las penalidades que han hecho de mi vida un tormento, me amarga hoy hasta las horas que para todos son de alivio y reposo.

Pero oye: si aquí en este lugar me dan tumba prestada, que pronto envíe Antioquia por mis huesos: a ella le pertenecen; tú y mis amigos haréis que los sepulten en el valle de Medellín o cerca de la tumlsa de Cordoba" (1). tioqueña.

Tal la donación que hiciera Isaacs de sus restos a la tierra an-

A ella cantará en dos de sus más altas inspiraciones: Río Moro y La Tierra de Córdoba. "En las estrofas de la primera, escribe Gómez Restrepo, está todo Isaacs con su espíritu aventurero, su amor a la naturalez? selvática, a las exploraciones lejanas y a la existencia libre y solitaria. Hasta la forma métrica es nueva y tiene su encanto: octavas asonentadas con los versos finales en rima consonante. "Río Moro", dice Isaacs en una nota, es un hermoso y caudaloso río que se encuentra entre Sonsón y Victoria, en el camino de Antioquia al Magdalena, en medio de la naturaleza más salvaje y pintoresca".

"Pero la producción más importante de los últimos años de Isaacs, dice el autor citado, fue el canto titulado La Tierra de Córdoba; cariñoso homenaje a Antioquia y a su raza, con la cual creía él tener afinidades por la sangre hebrea que llevaba en sus venas, ya que tradicionalmente, aunque sin comprobación histórica, se ha atribuído procedencia oriental a aquel pueblo por la habilidad comercial de sus hijos y la belleza de sus mujeres. Isaacs, que había perdido el afecto a su ciudad natal, se lo conservó muy grande a Antioquia, y ese sentimiento le inspiró un bellísimo canto, cuyas estrofas fluyen con un ritmo original y exquisito, como puede verse en las siguientes:

$\mathrm{Y}$ tus colonos van de cumbre en cumbre al septentrión y al sur,

segando vasta selvas, bajo dosel de nubes:

vigor es su derecho, y su alma la segur.

Desde Anaime y Nabarco hasta las fuentes hoscas del Guarinó,

los Ardes son el huerto feraz de tu simiente, vestíbulo de Arcadias que tu poder creó.

"Véase un rasgo galante sobre las mujeres antioqueñas y sobre la ciudad de Medellín:

Bellas y pudibundas como fueron

las hijas de Jessé,

en árabe tocado rebosan sus cabellos, refulgen en sus ojos las noches de Kedén.

1) - Repertorio Histórico. Oigano de la Academia Antioqueña de Historia, Nơ 141 del 20 de junio de 1938, págs. 708-709, Medellín. 
En el lujoso valle do serpean corrientes de zafir, al sol que la enamora, detiene y embelesa, cristiana sulamita, la hermosa Medellín.

¡Cómo la miro en estrelladas noches en mis sueños aún!

formándole cojines se agrupan los alcores, la cubren las montañas con su azulino tul" (2).

Precisamente en 1913, con motivo del Centenario de la Independencia de Antioquia, el citado historiador y crítico fue comisionado por los deudos de Isaacs para hacer entrega a Antioquia del manuscrito de este poema.

No estará de más, según pienso, transcribir para las páginas de la Revista Universidad Pontificia Bolivariana, las fichas que omitió MicGrady en su trabajo bibliográfico sobre Isaacs. El folleto aludido lleva por título el siguiente: La Gran Apoteosis de Isaacs. Colección de documentos, discursos, relativos a los honores hechos a la memoria y restos del cantor de La Tierra de Córdoba. Medellín, Imprenta Oficial. 1905.

Se trata de una publicación de 22,5 x 15 cms., editada en sencillo papel periódioo y con un total de 140 páginas. Iníciase con un artículo titulado: La Gran Apoteosis de Isaacs, Medellín, abril de 1905, (págs. 3-4).

Siguen en las páginas 5-12 documentos relativos a la exhumación de los restos del poeta. Y a la recepción de sus restos en Medellín se refieren los documentos de las páginas 31-39, y a los funerales, apoteosis e inhumación, los de las páginas 66-73.

En las páginas 115-117 se hallan tres telegramas relativos a los honores tributados a los restos del poeta en la ciudad de Medellín.

Hasta aquí la que denominaríamos literatura oficial y documental del folleto.

Léanse a continuación las diversas piezas bibliográficas contenidas en esta publicación y que pueden y deben adicionar detalladamente el ensayo de McGrady sobre Isaacs:

-Anónimo, Jorge Isaacs, (págs. 17-18). De El Tolima.

-Bonis J. M., (págs. 19-20). Carta del secretario de la "Junta Isaacs" de Bogotá. De Lectura Amena.

2) - Antonio Gómez Restrepo: "Historia de la Literatura Colombiana". Tomo IV. Imprenta Nacional, Bogotá, 1946, págs. 179 y 195-196. Conocida es la vinculación de Isaacs a Antioquia, y hasta su desafortunado sarampión revolucionario en 1876 y 1879. En la última oportunidad se proclamó y actuó brevemente como Jefe Político y Militar de Antioquia. En la guerra de 1860 tocóle ai General Juan Clímaco Arbeláez vivir bajo la misma tolda con Isaacs, Eliseo Arbeláez y Fortunato Cabal. Con el primero viajó a Sonsón, tras la fama y la obra del poeta del maíz, Gregorio Gutiérrez González. Seguramente proviene de aquí su amistad con el primero de los nombrados. 
-Méndez Valencia, Jorge. En la Velada Isaacs, (págs. 20-21). De El Santo y Seña.

-Isaacs, Lisímaco. Discurso (pág. 22). De Lectura Amena. y Seña.

-Arbeláez, Juan Clímaco. Discurso (págs. 22-25). De El Santo

-Vélez, Marceliano. Discurso (págs. 25-28). De El Santo y Seña.

-Grillo, Maximiliano. Palabras y recitación. En la Velada Isaacs, (págs. 28-30).

-Acta de la recepción de los restos del poeta Jorge Isaacs, (páginas 39-41). De Lectura Amena.

-Anónimo. Jorge Isaacs, (págs. 41-42). De Vida Nueva.

-Anónimo. Jorge Isaacs, (págs. 42-43). De La Patria.

zación.

-De Greiff, Luis. Jorge Isaacs, (págs. 44-46). De La Organi-

-Agudelo, Avelino. Discurso, a nombre del Gobierno Nacional, en la recepción de los restos de Jorge Isaacs, (págs. 46-47). De La Organización.

-Cano, Fidel. Discurso en la recepción de los restos del poeta Jorge Isaacs, (págs. 47-49). De La Lectura.

-Ramírez G., Enrique. Discurso en la recepción de los restos de Jorge Isaacs, (págs. 49-52). De La Miscelánea.

-Ospina, Lino R. Discurso en la recepción de los restos de Jorge Isaacs, (págs. 53-55). De La Miscelánea.

-Botero Guerra, Camilo. Discurso en la recepción de los restos de Jorge Isaacs, (págs. 55-58). De Lectura Amena.

-Fernández, Enrique W. A Jorge Isaacs. En la recepción de sus restos (5 cuartetos), (págs. 58-59). De Lectura Amena.

- Muñoz, Francisco de Paula. Los restos de Jorge Isaacs, (págs. 59-60). De Artículos y Discursos.

-Botero Guerra, Camilo. Carta del secretario de la "Junta Isaacs", (págs. 60-63). De El Santo y Seña.

-Dei Busio, Félix María. Así siente el pueblo, (págs. 63-64). De El Santo y Seña. La Prensa.

-Uribe Gómez, Pedro. Los restos de Isaacs, (págs. 64-65). De

--Tejada Córdoba B. Los restos de Isaacs. Para La Patria, (páginas 74-78). De La Patria.

-U. En honor de Isaacs, (págs. 79-81). De La Prensa. zación.

-Agudelo, Avelino. Jorge Isaacs, (págs. 81-86). De La Organi-

-Latorre, Luis E. Apoteosis, (págs. 86-87). De La Organización. Organización.

-Botero Guerra, Camilo. Por gratitud, (págs. 88-89). De La lánea.

-M.T.M. La Apoteosis de Isaacs, (págs. 89-92). De La MisceLectura Amena. (págs. 97-103).

-Restrepo, Carlos E. Discurso en el cementerio de San Pedro, 
(págs. 103-107).

-Ospina, Pedro Nel. Discurso en el cementerio de San Pedro, 107-112).

-Cano, Fidel. Discurso en el cementerio de San Pedro, (págs.

-Restrepo Eusse, Alvaro. Discurso, (págs. 113-115).

De La Miscelánea.

-Botero Guerra, Camilo. La gloria del bardo, (págs. 117-128).

-Rivera y Garrido, Luciano. En el hogar de mis mayores, (páginas 130-135). De El Heraldo, Bogotá.

bril. Bogotá.

-Jorge Isaacs, (pág. 136). De La Caridad, N 5 del 29 de a-

-Isaacs, Lisímaco. Gratitud de la Familia Isaacs. Párrafos de una carta, (pág. 137).

-María, (págs. 138-139). De El Espectador.

140).

-Botero Guerra, Camilo. Párrafos de un discurso (págs. 139-

38 títulos especializados bibliográficos sobre los homenajes rendidos a Isaacs con motivo de la traslación de sus restos en 1905 a la ciudad capital de Antioquia, bien merecen una detallada recensión, porque añaden casi un $10 \%$ más a los recogidos por McGrady.

Nada más necesario e imprescindible al investigador de todos los tiempos, máxime al de la época actual, lo que se puede denominar ciencia bibliográfica. Porque gracias a ella la dura labor investigativa se torna más fácil y sedante. $\mathrm{Y}$ los resultados vienen a ser inmensamente más favorables y benéficos.

Un poco tarde llegó a Colombia el cultivo de esta ciencia, y sigue todavía, a pesar de las labores admirables y patrióticas del Instituto Caro y Cuervo de Bogotá, en una áurea mediocridad. Hace tiempo debería existir un Boletín Bibliográfico a escala nacional y con una periodicidad mensual o al menos bimensual, que fuera el común denominador de la producción bibliográfica colombiana en el mes o meses anteriores. Con base en él, se elaboraría el anuario que recogiera la proaucción bibliográfica a escala nacional.

No es suficiente, a mi entender, el Anuario Bibliográfico que fundara en buena hora el lamentado Doctor Rubén Pérez Ortiz, y que por fortuna viene apareciendo desde 1951. Seguro estcy de que en él aparece solamente un $\mathbf{5 0 \%}$ de la bibliografía colombiana. Porque resulta imposible reunir cuanto se publica en la prensa y en las revistas, cuando ni siquiera se puede controlar y reseñar la bibliografía propiamente tal.

Debería fundarse una Asociación o Instituto de Bibliografía Colombiana, debidamente organizado y financiado a escala nacional, que se ocupara con amplitud y eficiencia de este gran problema cultural colombiano. Porque a las alturas de 1972, no puede Colombia darse el lujo -mejor aún, cometer la torpeza- de desconocer una gran parte de cuanto se publica a todo lo ancho y largo de su territorio. 
El referido Instituto, con sede en Bogotá, organizaría filiales suyos en los departamentos, exactamente en las ciudades capitales. Aquí, por medio de las Academias de Historia, las Universidades y los mismos interesados en estos estudios, iniciaría el que llamaría control bibliográfico sistemático de todas las publicaciones en la prensa y en las revistas, además de la producción rigurosamente bibliográfica. Los informes de Academias y Centros de Historia, de los corresponsales y universidades, alimentarían el Boletín Bibliográfico mensual o bimensual que originaría al final de cada año el gran Anuario Bibliográfico, casi completo y perfecto y amplio exponente de la actividad bibliográfica colombiana en el decurso del año.

Estoy seguro de que, con un poco de interés y de organización, este ideal no es imposible. Porque ciertamente muchas de las instituciones citadas y muchos interesados en el trascendental tema de la bibliografía y en el adelanto y progreso de esta ciencia en Colombia, dedicarían sus conocimientos y entusiasmo para llevar adelante una obra de tanta importancia y significación para el progreso cultural colombiano.

"Investigar en Colombia, leía no hace mucho en el diario El Tiempo de Bogotá, constituye una quijotada y, con frecuencia, un suicidio económico. Sin embargo, nuestro progreso y nuestra independencia cultural están basados en el conocimiento que de nuestra propia realidad tengamos y en lograr su desarrollo pleno con métodos adecuados a ella.

Un país como el nuestro enfrenta en el campo científico muchos problemas. Algunos de ellos están basados en su falta de recursos económicos y otros en su carencia de personal calificado en algunos campos.

Para impulsar la ciencia y la tecnología nacionales, sería necesario tomar muchas medidas en diferentes campos. Ante todo, se debe:ia estimular a aquéllos que ya están trabajando en algunos aspectos útiles para el país. Esta ayuda no se debe canalizar solo a las universidades, porque con frecuencia no están vinculados a ellas. El apoyo se debe dar ampliamente, sin criterio de rosca, ni tantas trabas burocráticas. Al establecer una escala de importancia en los trabajos que se van a apoyar, se les debe dar preferencia a aquéllos que se refieran al mejor conocimiento del hombre y del medio colombianos.

También se debería facilitar la publicación de estos trabajos, para que no se quedaran ignorados, como sucede con frecuencia. Asimismo, se debería publicar bibliografía nacional, basada en un buen archivo de los trabajos científicos realizados en el país" (3).

Las anteriores afirmaciones, parecen escritas para la investigación bibliográfica colombiana, que se puede y se debe extender a todos los campos, con beneficio inmenso para la comunidad.

Nada más importante y más patriótico que el apoyo oficial a todo cuanto sepa a cultura a través de sus multiformes manifestaciones.

3) - Artículo El Progreso Cientifico, por Alvaro López Pardo, pág. 4 A. 21 de febrero de 1972. 
Con base en él, y aún cuando el olvido oficial incida, como en veces sucede, sobre las manifestaciones culturales, las entidades y los particulares deben vincularse a estos movimientos. Los diarios y revistas deberían ser permanentes captadores y divulgadores de las novedades bibliográficas a escala departamental y citadina, con lo cual prestarían ingente servicio a la comunidad y al progreso y actualización bibliográfica. Y las Academias y Centros de Historia y Casas de Cultura pueden y deben prestar permanente y eficaz colaboración a estas actitvidades intelectuales.

Mientras la ciencia de la bibliografía no se cultive con diligencia y espíritu crítico, patriótico y nacionalista, no se podrá exigir a investigadores, historiadores y científicos, una total responsabilidad en sus producciones, la cual supone, como es obvio, el conocimiento y utilización de la más compleja y selecta producción bibliográfica.

Ojalá sirvan las anteriores líneas para impeler a cuantos se sientan llamados a tan importante tarea, a colaborar de manera decidida y permanente en asunto de tánta significación y necesidad para Colombia. 